\title{
RANCANG BANGUN SISTEM MONITORING AIR IRIGASI BERBASIS INTERNET OF THINGS PADA POMPA AIR BERTENAGA SURYA
}

\author{
Muhammad Afnan Habibi ${ }^{1}$, Bagus Prastyo ${ }^{2}$, Aldo Zulfikar Asror Zulkarnain ${ }^{3}$, Faj'run \\ Ni'am $^{4}$, Bunga Hidayati ${ }^{5}$
}

${ }^{1}$ Jurusan Teknik Elektro, Universitas Negeri Malang

Email: afnan.habibi.ft@um.ac.id

${ }^{2}$ Jurusan Teknik Elektro, Universitas Negeri Malang

Email: bagustyo171@gmail.com

${ }^{3}$ Jurusan Teknik Elektro, Universitas Negeri Malang

Email: zulfikar.aldo.3@gmail.com

${ }^{4}$ Jurusan Teknik Elektro, Universitas Negeri Malang

Email: niamfajrun@gmail.com

${ }^{5}$ Jurusan Ekonomi Pembangunan, Universitas Negeri Malang

Email: bunga.hidayati.fe@um.ac.id

\begin{abstract}
Agriculture is the main and fundamental activity on this earth. However, the agricultural sector has not contributed significantly to the mitigation of natural disasters such as loss of biodiversity, migration of watercourses, lack of clean water, and drought. Based on the results of the population census in the last 10 years, Indonesia's population growth rate reaches $1.25 \%$ every year. The consequence of the current phenomenon is the scarcity of food and the shrinking of the people's economic condition. The limited availability of irrigation water is a major agricultural problem experienced by the Tawang Makmur Farmers Group (KTTM). Several solutions have been implemented such as scheduling the opening of drainage channels provided by the village and renting diesel pumps on a regular basis. But in fact, these solutions have not been able to properly address the problems experienced by KTTM. So this paper offers a solar-powered photovoltaic ( $P V)$ water pump irrigation system that is integrated with the Internet of Things. Since 1970, PV has become an alternative that is often applied to agricultural irrigation systems in rural areas. The system built in this paper utilizes solar power as a power source that supplies water pumps. The Internet of Things is integrated into the system, enabling farmers to monitor and control agricultural areas in real-time and wirelessly through an adequate internet network.
\end{abstract}

Keywords: Internet of Things; Irrigation Monitoring; Rural Agriculture; Photovoltaic; Electric Water Pump

ABSTRAK
Pertanian merupakan aktifitas pokok nan fundamental di bumi ini. Akan tetapi, sektor pertanian belum memberikan kontribusi secara signifikan mengenai mitigasi bencana alam seperti kehilangan keragaman hayati, migrasi aliran air, kekurangan air bersih, dan kekeringan. Berdasarkan hasil sensus penduduk dalam 10 tahun terakhir, laju pertumbuhan penduduk Indonesia mencapai $1.25 \%$ dalam setiap tahunnya. Konsekuensi dari fenomena yang terjadi saat ini adalah kelangkaan bahan pangan dan penyusutan kondisi ekonomi rakyat. Ketersediaan air irigasi yang terbatas menjadi masalah besar pertanian yang dialami oleh Kelompok Tani Tawang Makmur (KTTM). Beberapa solusi telah diterapkan seperti penjadwalan pembukaan saluran drainase yang disediakan oleh pihak desa, dan menyewa pompa diesel secara berkala. Namun faktanya, solusi tersebut belum mampu mengatasi permasalahan yang dialami oleh KTTM secara tepat. Sehingga makalah ini menawarkan sistem irigasi pompa air photovoltaic (PV) bertenaga surya yang terintegrasi dengan Internet of Things. Sejak tahun 1970, PV telah menjadi alternatif yang sering diterapkan pada sistem irigasi lahan pertanian daerah pedesaan. Sistem yang dibangun pada makalah ini memanfaatkan tenaga surya sebagai sumber daya yang menyuplai pompa air. Internet of Things yang diintegrasikan pada sistem, memungkinkan para petani untuk melakukan monitoring dan kontrol terhadap area pertanian secara real-time dan nirkabel melalui jaringan internet yang memadai.

Kata Kunci: Internet of Things; Monitoring Irigasi; Pertanian Pedesaan; Photovoltaic; Pompa Air Listrik 


\section{PENDAHULUAN}

\section{Latar Belakang}

Saat ini dunia berada pada posisi perubahan kehidupan secara eksponensial pada berbagai sektor. Terdapat beberapa tren teknologi yang dikembangkan pada revolusi industri 4.0. Berbeda mencolok dengan revolusi industri tahap sebelumnya, revolusi industri 4.0 ditandai dengan berkembangnya Internet of Things yang diikuti teknologi baru dalam data sains, kecerdasan buatan, robotik, cloud, cetak tiga dimensi, dan teknologi nano (Ghufron, 2018). Konsep Internet of Things mencakup 3 elemen utama yaitu (1) benda fisik atau nyata yang telah diintegrasikan pada modul sensor, (2) koneksi internet, dan (3) pusat data pada server untuk menyimpan data ataupun informasi dari aplikasi (Setiadi \& Abdul Muhaemin, 2018).

Smart agriculture system adalah istilah baru yang muncul dalam implementasi IoT pada bidang pertanian. Bidang pertanian menjadi objek yang dipusatkan untuk memaksimalkan hasil panen petani melalui aktifitas kontrol dan monitoring parameter-parameter fisik tertentu secara realtime. Smart agriculture merupakan sebuah konsep dimana teknologi informasi dan komunikasi diimplementasikan untuk mengelola semua aktifitas dan proses yang berkaitan dengan ranah pertanian (Marcu, Suciu, Balaceanu, \& Banaru, 2019). Belakangan ini teknologi IoT populer diimplementasikan pada smart agriculture system dalam mencapai pertanian presisi. Istilah pertanian presisi mengacu pada aktifitas apa pun yang membuat praktik pertanian lebih terkontrol dan lebih akurat dalam hal memelihara ternak dan menanam tanaman (Ajit Kumar, 2020).

Pertanian menjadi sektor pekerjaan yang diisi lebih dari setengah jumlah populasi manusia di seluruh dunia. Sektor ini menyediakan pangan bagi sebagian besar penduduk dan memberikan lapangan pekerjaan bagi semua angkatan kerja yang ada(Abdul Wahid, Amira Mustarin, 2019). Dalam sebuah studi (Marchianti, Nurus Sakinah, \& Diniyah, 2017), pertanian adalah suatu aktifitas pendayagunaan sumber daya hayati yang dikelola manusia untuk memproduksi bahan pangan, bahan baku industri, atau sumber energi, serta untuk mengelola lingkungan hidupnya. Secara umum, aktifitas pertanian meliputi (1) proses pembibitan, (2) proses perawatan, dan (3) proses pemanenan. Selain pembibitan, perawatan merupakan rangkaian proses yang membutuhkan perhatian khusus dalam upaya memaksimalkan hasil panen pada sebuah domain usaha pertanian.

Studi kasus yang diangkat pada artikel ini adalah permasalahan yang dialami oleh Kelompok Tani Tawang Makmur (KTTM) Desa Bendosewu, yang berada di Kabupaten Blitar. KTTM beranggotakan lebih dari 25 kepala keluarga, dengan total luas lahan area pertanian sekitar 5 ha seperti yang tampak pada Gambar 1. Para petani tersebut mengalami kesulitan dalam proses irigasi lahan pertanian yang mereka miliki. Penjadwalan irigasi dan pemupukan yang tepat sangat penting untuk pengembangan tanaman yang tepat (Sushanth \& Sujatha, 2018).

Meskipun fasilitas saluran drainase telah disediakan oleh pihak desa, namun fasilitas tersebut belum mampu menyuplai kebutuhan air pada lahan pertanian para petani. Hal itu terjadi karena jadwal pembukaan saluran drainase yang terbatas. Sehingga mengancam kondisi tanaman karena kekurangan air. Solusi lain yang pernah diterapkan untuk mengairi lahan pertanian mereka adalah menyewa pompa motor diesel. Solusi tersebut dinilai kurang efektif karena membutuhkan biaya yang tidak sedikit. Mengingat keuntungan yang didapatkan petani setiap bulan relatif kecil, sehingga kondisi tersebut akan mengancam keadaan ekonomi para petani dan keluarganya. 


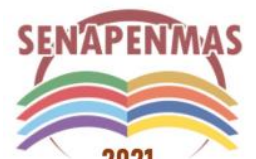

2021
Seminar Nasional Hasil Penelitian dan Pengabdian Kepada Masyarakat 2021 Pengembangan Ekonomi Bangsa Melalui Inovasi Digital Hasil Penelitian dan Pengabdian Kepada Masyarakat Jakarta, 21 Oktober 2021

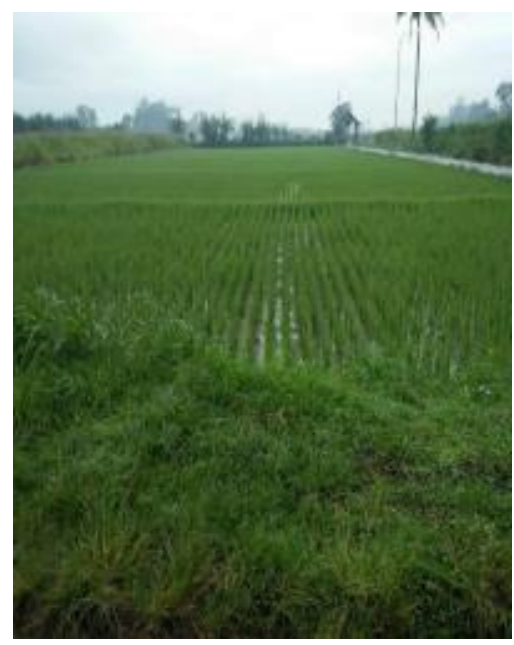

Gambar 1. Kondisi lahan pertanian KTTM

Terdapat sebuah studi yang mengembangkan sistem irigasi cerdas untuk monitoring dan kontrol bendungan berbasis IoT (Setiadi \& Abdul Muhaemin, 2018). Pada penelitian (Chetan Dwarkani, Ganesh Ram, Jagannathan, \& Priyatharshini, 2015) melakukan otomatisasi pada beberapa tugas pertanian. Sedangkan penelitian lain (Ferrández-Pastor, García-Chamizo, Nieto-Hidalgo, \& Mora-Martínez, 2018) mengembangkan suatu sistem otomatisasi untuk mewujudkan pertanian presisi. Solusi yang ditawarkan pada artikel ini adalah sistem irigasi pompa air bertenaga surya menggunakan photovoltaic (PV) berbasis Internet of Things (IoT). Sistem yang dirancang terdiri dari beberapa piranti yang memiliki fungsi saling terintegrasi. Arsitektur sistem menggunakan pengontrol utama berupa mikrokontroler ATMega 328 berbasis Arduino Uno yang terintegrasi dengan modul wifi ESP-8266 (ESP-01). Selain itu, juga terdapat beberapa sensor seperti sensor ultrasonik; sensor DHT11; serta soil moisture sensor.

Sensor ultrasonik digunakan untuk memonitoring ketinggian air yang ditampung pada tangki penyimpanan air irigasi. Selain itu, kondisi suhu dan kelembaban disekitar area persawahan akan dideteksi oleh sensor DHT11 yang membaca data secara akurat. Soil moisture sensor merekam data kadar kelembapan pada tanah area persawahan untuk memastikan kondisi tanah baik untuk tanaman. Data-data parameter fisik tersebut diukur secara real-time dengan akurasi yang telah terkalibrasi. Papan Arduino Uno memiliki peran sebagai gateway IoT yang terhubung dengan modul wifi ESP-8266 (ESP-01). Akses yang digunakan oleh Arduino untuk mengirimkan data hasil pembacaan beberapa parameter fisik dari sensor menuju cloud adalah melalui jaringan internet, dimana fungsi modul wifi ESP-8266 (ESP-01) dibutuhkan dalam hal tersebut.

Tujuan penelitian yang hendak dicapai pada makalah ini adalah sistem yang dirancang mampu melakukan monitoring terhadap parameter tingkat ketinggian air pada tangki penyimpan air, kelembaban tanah, serta suhu dan kelembaban pada area pertanian. Sistem monitoring yang dirancang tersebut menggabungkan antara Internet of Things dengan manajemen cloud. Basis data yang digunakan pada sistem tersebut tersimpan pada ThingSpeak.

Capaian kontribusi yang diharapkan pada penerapan sistem yang diajukan ini ialah mampu mewujudkan pertanian presisi bagi kelompok tani tawang makmur. Monitoring dan manajemen irigasi lahan pertanian dapat dilakukan dengan efisien, sehingga produktifitas hasil panen akan meningkat, serta memperbaiki kehidupan ekonomi para petani.

\section{Rumusan Masalah}

Berdasarkan permasalahan yang dialami oleh kelompok tani tawang makmjur tersebut, adapun rumusan masalah yang diangkat ialah bagaimana perancangan sistem monitoring air irigasi berbasis internet of things pada pompa air bertenaga surya. 


\section{METODE PENELITIAN}

Salah satu hal yang menentukan keberhasilan maupun efektifitas dari sistem yang akan diimplementasikan melalui kegiatan penelitian adalah metode penelitian. Dalam metode penelitian menjelaskan tahapan-tahapan maupun alur penelitian yang akan dilakukan secara terstruktur berdasarkan penelitian yang akan dilakukan. Adapun beberapa tahapan metode penelitian yang dilakukan ditunjukkan pada gambar 2 .

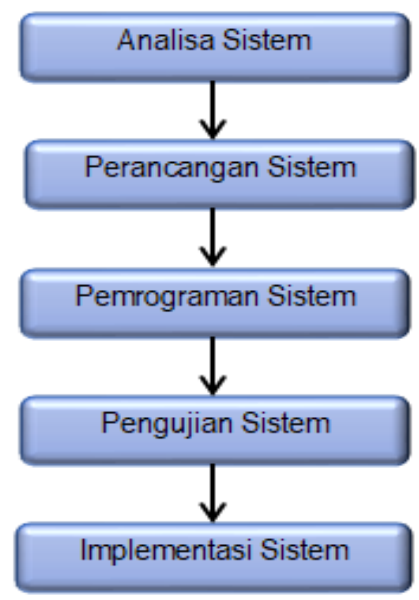

Gambar 2. Tahapan Metode Penelitian

\section{Analisa Sistem}

Pada tahap analisa sistem dilakukan dengan tujuan agar mengetahui kebutuhan-kebutuhan yang diperlukan dalam proses realisasi sistem yang dirancang. Kebutuhan tersebut meliputi data-data yang dibersumber dari studi literatur melalui artikel ilmiah, jurnal ilmiah, prosiding, dan lain sebagainya. Kebutuhan alat dan bahan yang dibutuhkan juga diuraikan pada analisa sistem. Melalui tahapan ini tujuan penelitian berupa perancangan sistem monitoring terhadap parameter tingkat ketinggian air pada tangki penyimpan air, kelembaban tanah, serta suhu dan kelembaban area pertanian dapat tercapai dengan baik.

\section{Perancangan Sistem}

Rancangan sistem berupa software dan hardware berdasarkan kebutuhan yang diperlukan untuk menjadi solusi terhadap permasalahan yang muncul dilakukan pada tahapan perancangan sistem. Untuk memberikan gambaran terhadap kinerja sistem, penulis mendesain diagram alir sistem yang ditunjukkan oleh gambar 3. Selain itu, dalam perancangan sistem ini juga dilakukan desain skematik rangkaian elektronik yang merepresentasikan pengkabelan (wiring) antara komponenkomponen yang digunakan pada sistem monitoring air irigasi (gambar X).

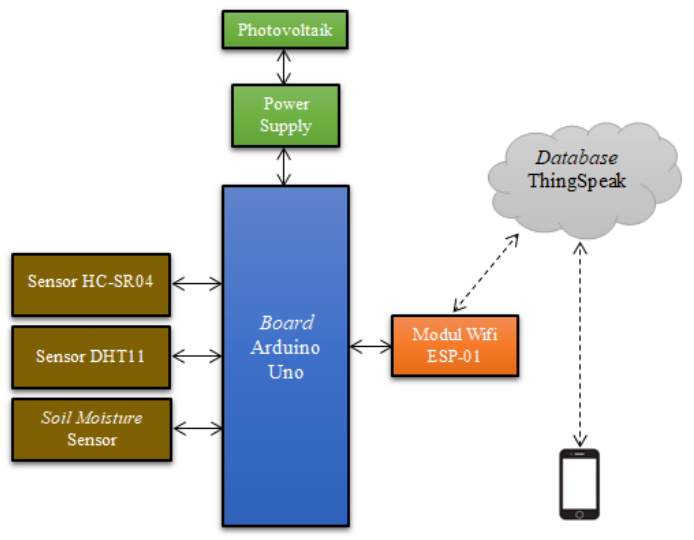

Gambar 3. Diagram Alir Sistem 


\section{Pemrograman Sistem}

Pada tahapan pemrograman sistem ini dilakukan pemrograman terhadap mikrokontroler Arduino Uno yang diintegrasikan dengan modul wifi ESP-8266 (ESP-01). Pada sistem yang dirancang, Arduino Uno memiliki peran penting sebagai pengontrol utama. Dimana pemrograman yang dilakukan tersebut memiliki tujuan agar mikrokontroler Arduino Uno mampu berfungsi seusai dengan tujuan sistem yang diharapkan. Pemrograman tersebut dilakukan melalui komputer/PC menggunakan software khusus berupa arduino IDE. Pada program yang dirancang, Arduino Uno yang telah diintegrasikan dengan ESP-01 harus mampu mengakuisisi data yang bersumber dari beberapa sensor serta mentransmisikan data-data tersebut menuju database berupa ThingSpeak secara real-time dengan koneksi internet.

\section{Pengujian Sistem}

Keberhasilan sistem dapat diketahui melalui tahapan ini. Sistem yang dirancang diuji berdasarkan fungsi dan keakuratan data yang diperoleh. Sehingga tahapan pengujian sistem bertujuan untuk menjamin dan memastikan bahwa sistem yang telah dirancang mampu berfungsi dengan baik sebagai solusi pada permasalahan yang terjadi.

\section{Implementasi Sistem}

Tahapan ini merupakan tahapan akhir yang menyatakan bahwa kinerja sistem telah menunjukkan hasil yang baik pada proses pengujian serta telah sesuai dengan target yang diharapkan dalam sistem monitoring air irigasi. Sehingga sistem yang dirancang telah siap untuk diimplementasikan dilapangan sebagai solusi yang dibutuhkan oleh kelompok tani tawang makmur untuk memonitoring sistem irigasi pada lahan pertanian mereka.

\section{HASIL DAN PEMBAHASAN}

Target dalam proses implementasi sistem adalah sistem ini mampu berfungsi sesuai kebutuhan dan target yang diinginkan untuk menjadi solusi terhadap permasalahan yang dialami oleh kelompok tani tawang makmur.

\section{Skematik Rangkaian Elektronik}

Pada skema rangkaian yang dirancang (Gambar 4), terdapat 3 sensor serta modul wifi ESP-01 yang dihubungkan dengan mikrokontroler Arduino Uno. Beberapa sensor tersebut memiliki fungsi yang berbeda-beda. Dimana sensor ultrasonik HC-SR04 memiliki fungsi untuk mendeteksi ketinggian air pada tangki penyimpanan air. Suhu dan kelembaban di area lahan pertanian dideteksi oleh sensor DHT11. Sedangkan kadar kelembaban tanah dideteksi oleh soil moisture sensor.

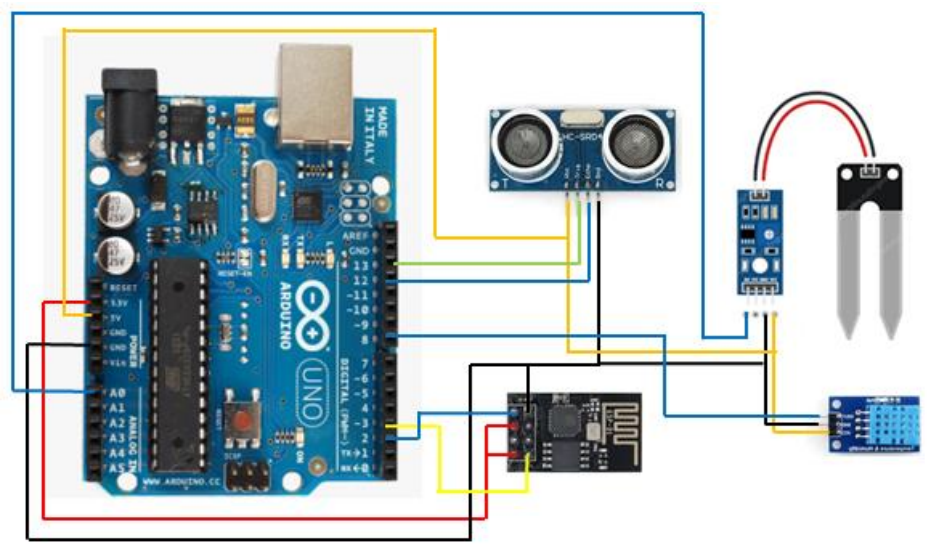

Gambar 4. Skema Rangkaian Elektronik 


\section{Instalasi Panel Surya dan Saluran Irigasi}

Pada gambar 5 menunjukkan lokasi instalasi sistem monitoring yang mampu mengoptimalkan manajemen sistem irigasi yang digunakan untuk memenuhi kebutuhan air pada tanaman para petani. Terdapat beberapa pipa, seperti yang tampak pada Gambar 6.a, yang terhubung sampai ke air tanah. Instalasi pompa tenaga surya membantu menyalurkan air tanah ke lahan pertanian melalui saluran irigasi seperti pada Gambar 6.b.

Sistem pompa air bertenaga surya menggunakan photovoltaik (PV) mampu menjadi solusi untuk menekan biaya yang dibutuhkan dalam proses irigasi lahan petanian seperti yang terlihat dalam Gambar 5. Photovoltaik yang digunakan untuk mengkonversi tenaga matahari menjadi suplai daya yang dibutuhkan oleh mikrokontroler Arduino Uno yang berarus DC. Selain itu, tenaga dari PV juga disimpan dalam baterai lalu dikonversi menjadi arus AC melalui inverter agar mampu dimanfaatkan sebagai sumber daya untuk mengaktifkan pompa air. Sehingga petani dapat mengamati beberapa data yang bersumber dari sensor-sensor yang digunakan secara real-time melalui database ThingSpeak.

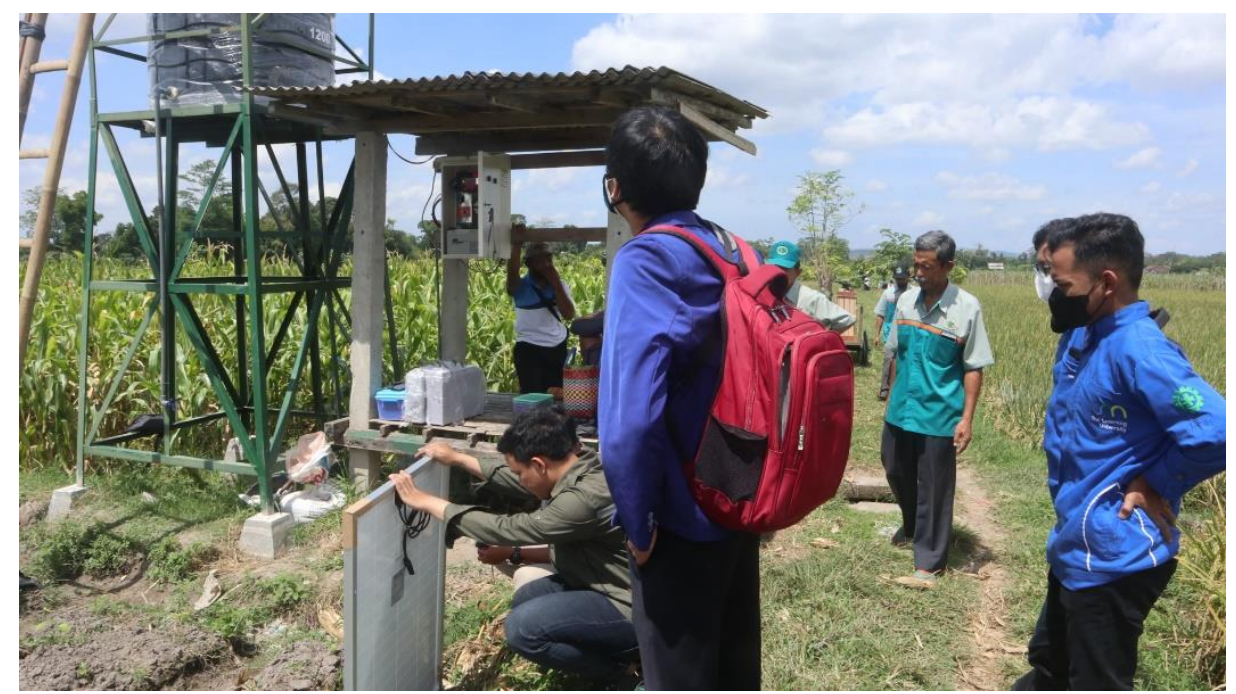

Gambar 5. Bangunan pusat panel kontrol dan tangi air

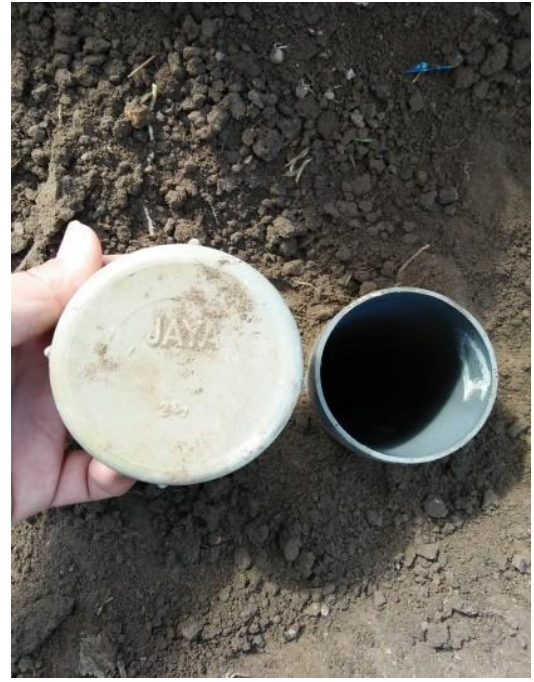

(a)

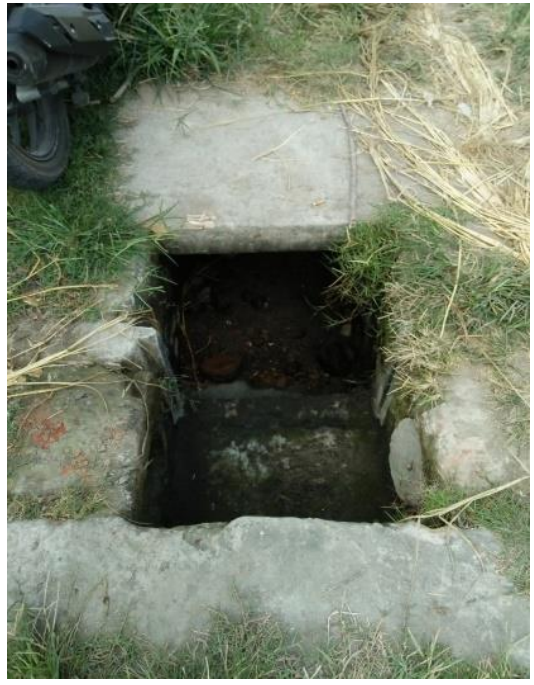

(b)

Gambar 6. Bentuk fisik a) sumur bor dan b) saluran air irigasi utama 


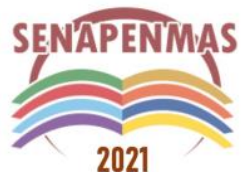

Seminar Nasional Hasil Penelitian dan Pengabdian Kepada Masyarakat 2021

Pengembangan Ekonomi Bangsa Melalui Inovasi Digital Hasil Penelitian dan Pengabdian Kepada Masyarakat Jakarta, 21 Oktober 2021

Pada gambar 7 menunjukkan pengukuran fisik kedalaman sumur dan ketinggian air sumur untuk menentukan kapasitas motor pompa, baterai, dan serangkaian PV. Komponen pendukung seperti pemutus arus, saklar, lampu indikator, serta perangkat IoT disusun rapi dalam sebuah kotak panel seperti Gambar 8 dan 9.

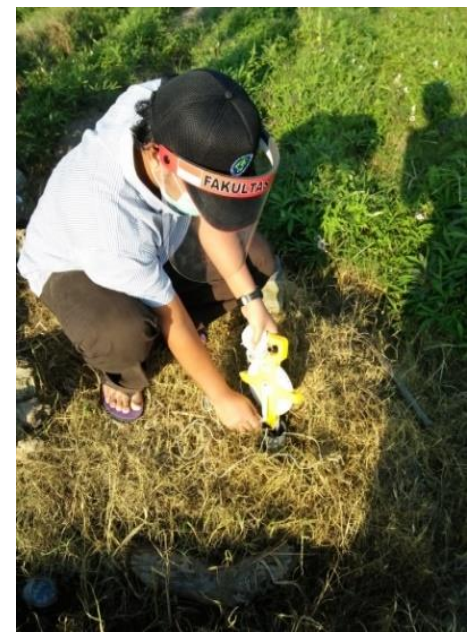

Gambar 7. Proses pengukuran pipa saluran air irigasi

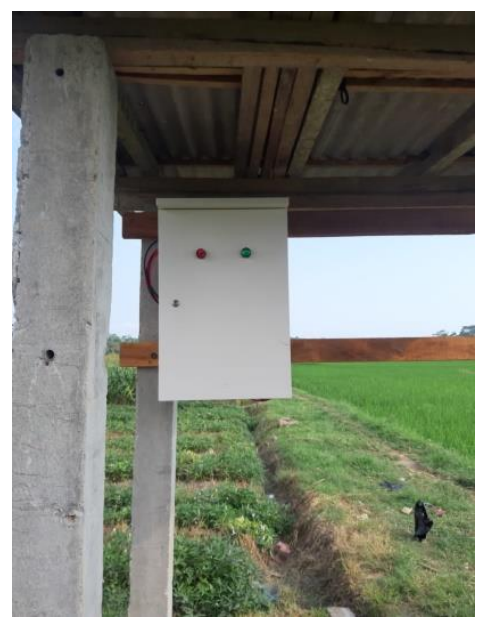

Gambar 8. Panel kontrol tampak luar

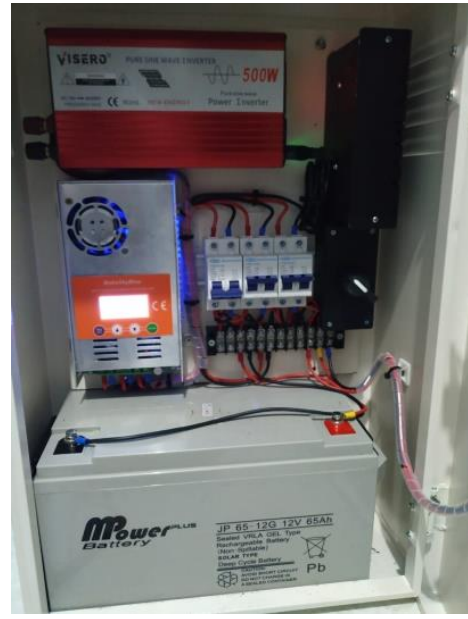

Gambar 9. Panel kontrol tampak dalam 


\section{Monitoring Sistem Irigasi}

Selain mengintegraiskan PV untuk memenuhi kebutuhan suplai daya, pada sistem monitoring irigasi yang dirancang mengintegrasikan teknologi internet of things, sehingga seluruh parameter data yang diperoleh hanya dapat dipantau melalui jaringan internet. Data-data yang diperoleh dari beberapa sensor yang digunakan pada sistem akan diproses oleh mikrokontroler Arduino Uno hingga data tersebut dapat dibaca dan dianalisis. Pemrosesan data melibatkan modul wifi ESP-01 yang memiliki fungsi untuk mengirimkan data-data tersebut secara real-time menuju platform database ThingSpeak menggunakan jaringan internet yang memadai. Sehingga jika ketersediaan internet terbatas, gangguan akan muncul dalam proses pengiriman data. Melalui ThingSpeak, data dapat dibaca dengan mudah serta dapat dianalisis oleh petani untuk menentukan keputusan yang tepat dalam proses manajemen air pada irigasi lahan pertanian. Adapun flowchart sistem monitoring irigasi ditunjukkan pada gambar 10.

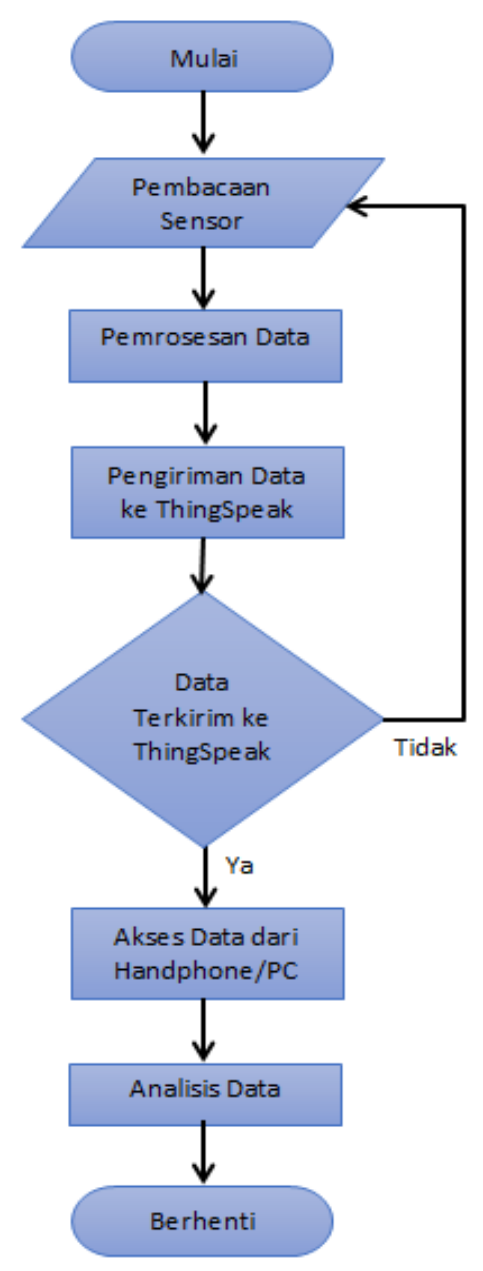

Gambar 10. Flowchart sistem monitoring

Kualitas jaringan internet yang tersedia sangat memberikan pengaruh terhadap keberhasilan proses transfer data. Data yang dikirimkan menuju ThingSpeak ialah data yang bersumber dari hasil pembacaan sensor ultrasonik HC-SR04, sensor DHT11, serta soil moisture sensor. Seluruh data tersebut dikirimkan secara real-time dengan interval waktu kurang lebih selama 60 detik. Akses data yang dapat dilakukan menggunakan handphone maupun PC yang telah terkoneksi dengan internet. Tampilan hasil monitoring dari pembacaan seluruh parameter data sensor yang berhasil dikirimkan pada ThingSpeak ditunjukkan pada beberapa gambar dibawah ini. 


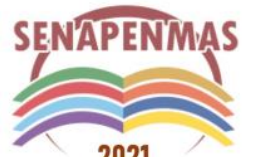

2021
Seminar Nasional Hasil Penelitian dan Pengabdian Kepada Masyarakat 2021

Pengembangan Ekonomi Bangsa Melalui Inovasi Digital Hasil Penelitian dan Pengabdian Kepada Masyarakat Jakarta, 21 Oktober 2021

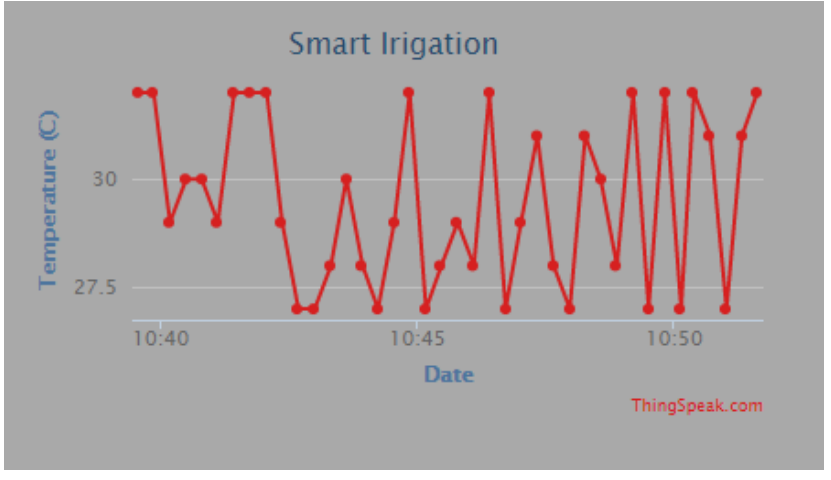

(a)

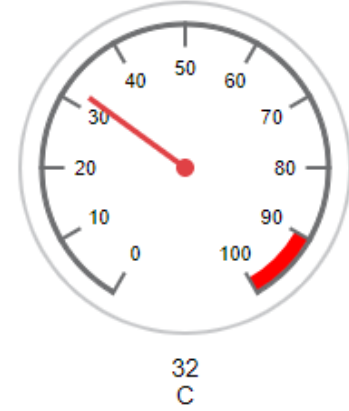

(b)

Gambar 11. Data pembacaan suhu a) Grafik dan b) Gauge

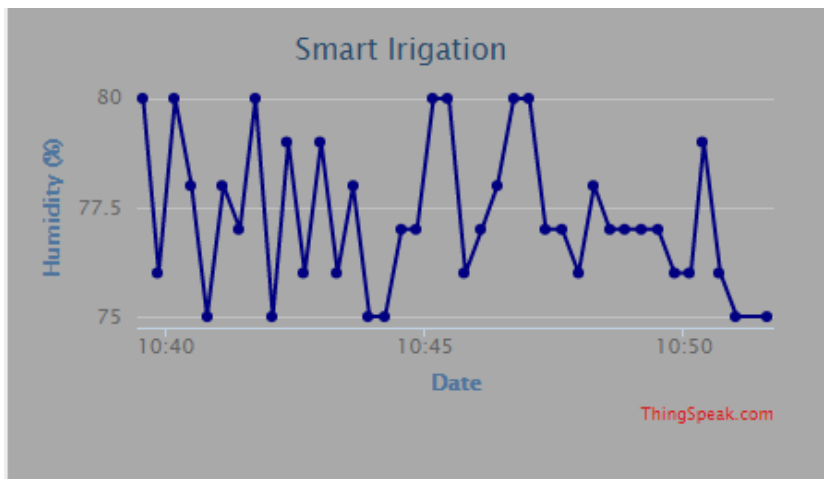

(a)

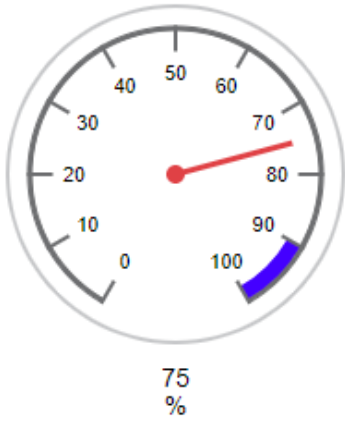

(b)

Gambar 12. Data pembacaan kelembaban a) Grafik dan b) Gauge

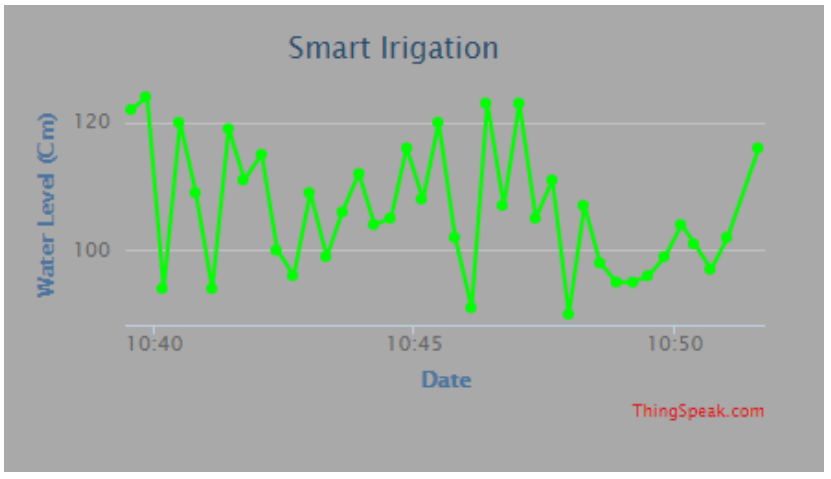

(a)

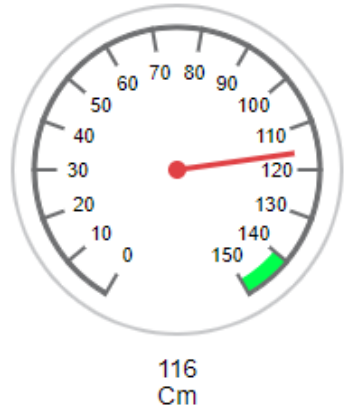

(b)

Gambar 13. Data pembacaan tingkat ketinggian air a) Grafik dan b) Gauge

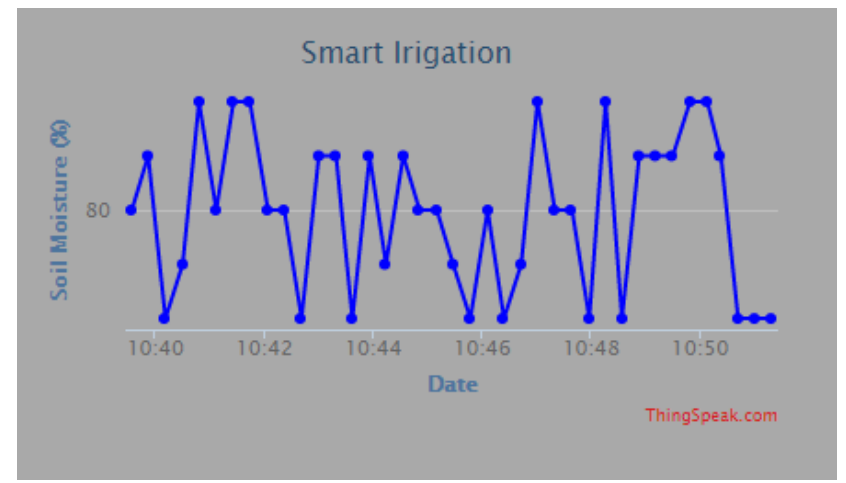

(a)

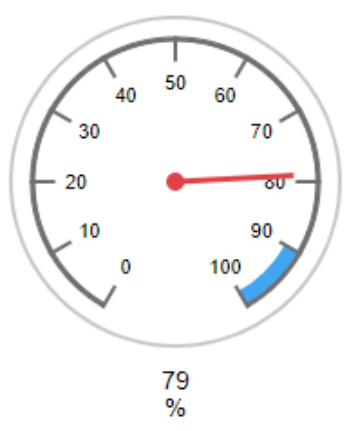

(b) 
Gambar 14. Data pembacaan tingkat kelembaban tanah a) Grafik dan b) Gauge

\section{KESIMPULAN DAN SARAN}

Sistem irigasi dengan pompa air bertenaga surya berbasis Internet of Things ini mampu menjawab kebutuhan Kelompok Tani Tawang Makmur (KTTM) dalam memudahkan petani untuk memanajemen suplai air pada lahan pertanian mereka. Beberapa data parameter fisik yang mampu diidentifikasi oleh beberapa sensor pada sistem ditampilkan pada ThingSpeak melalui representasi grafik dan gauge. Dimana data-data tersebut menjadi acuan petani dalam menentukan manajemen air irigasi dengan baik dan tepat. Data ketinggian air menjadi landasan pertimbangan petani dalam menyalakan pompa air. Sedangkan data tingkat kelembaban tanah menjadi pertimbangan utama petani untuk mengalirkan air dari tangki penyimpan air menuju lahan pertanian mereka. Tindak lanjut pada penelitian berikutnya, mengembangkan sistem menjadi sistem monitoring dan kontrol irigasi. Selain itu, pengembangan mobile application perlu dilakukan untuk menjadi antarmuka dalam melakukan kontrol dan monitoring pada sistem irigasi lahan pertanian Kelompok Tani Tawang Makmur (KTTM).

Ucapan Terima Kasih (Acknowledgement)

Seluruh kegiatan ini mendapat bantuan dana dari PNBP UM 2021 dan disalurkan oleh tim penelitian dan pengabdian jurusan Teknik Elektro Universitas Negeri Malang kepada Kelompok Tani Tawang Makmur (KTTM) mengembangkan potensi pertanian di Desa Bendosewu.

\section{REFERENSI}

Abdul Wahid, Amira Mustarin, L. L. (2019). Analisis Kelayakan Usaha Industri Jagung Marning (di Kelurahan Caile Kecamatan Ujung Bulu Kabupaten Bulukumba (Studi Kasus UKM Pinisi Bulukumba). Jurnal Pendidikan Teknologi Pertanian, 5(2), 1-13.

Ajit Kumar, S. (2020). Applications of IoT in Agricultural System. International Journal of Agricultural Science and Food Technology, 6(1), 041-045. https://doi.org/10.17352/2455-815x.000053

Chetan Dwarkani, M., Ganesh Ram, R., Jagannathan, S., \& Priyatharshini, R. (2015). Smart farming system using sensors for agricultural task automation. Proceedings - 2015 IEEE International Conference on Technological Innovations in ICT for Agriculture and Rural Development, TIAR 2015, (Tiar), 49-53. https://doi.org/10.1109/TIAR.2015.7358530

Ferrández-Pastor, F. J., García-Chamizo, J. M., Nieto-Hidalgo, M., \& Mora-Martínez, J. (2018). Precision agriculture design method using a distributed computing architecture on internet of things context. Sensors (Switzerland), 18(6). https://doi.org/10.3390/s18061731

Ghufron, G. (2018). Revolusi Industri 4.0: Tantangan, Peluang, Dan Solusi Bagi Dunia Pendidikan. Seminar Nasional Dan Diskusi Panel Multidisiplin Hasil Penelitian Dan Pengabdian Kepada Masyarakat 2018, 1(1), 332-337.

Marchianti, A., Nurus Sakinah, E., \& Diniyah, N. et al. (2017). Digital Repository Universitas Jember Digital Repository Universitas Jember. Efektifitas Penyuluhan Gizi Pada Kelompok 1000 HPK Dalam Meningkatkan Pengetahuan Dan Sikap Kesadaran Gizi, 3(3), 69-70.

Marcu, I. M., Suciu, G., Balaceanu, C. M., \& Banaru, A. (2019). IoT based System for Smart Agriculture. Proceedings of the 11th International Conference on Electronics, Computers and Artificial Intelligence, ECAI 2019, 27-30. https://doi.org/10.1109/ECAI46879.2019.9041952

Setiadi, D., \& Abdul Muhaemin, M. N. (2018). PENERAPAN INTERNET OF THINGS (IoT) PADA SISTEM MONITORING IRIGASI (SMART IRIGASI). Infotronik: Jurnal Teknologi Informasi Dan Elektronika, 3(2), 95. https://doi.org/10.32897/infotronik.2018.3.2.108

Sushanth, G., \& Sujatha, S. (2018). IOT Based Smart Agriculture System. 2018 International Conference on Wireless Communications, Signal Processing and Networking, WiSPNET 2018, 1-4. https://doi.org/10.1109/WiSPNET.2018.8538702 